\title{
Maurizio Melai, Les Derniers Feux de la tragédie classique au temps du romantisme
}

\section{Valentina Ponzetto}

\section{(2) OpenEdition}

10 Journals

\section{Édition électronique}

URL : http://journals.openedition.org/studifrancesi/5353

DOI : 10.4000/studifrancesi.5353

ISSN : 2421-5856

Éditeur

Rosenberg \& Sellier

\section{Édition imprimée}

Date de publication : 1 décembre 2016

Pagination : 534-535

ISSN : 0039-2944

\section{Référence électronique}

Valentina Ponzetto, «Maurizio Melai, Les Derniers Feux de la tragédie classique au temps du romantisme », Studi Francesi [En ligne], 180 (LX | III) | 2016, mis en ligne le 01 janvier 2017, consulté le 18 septembre 2020. URL : http://journals.openedition.org/studifrancesi/5353 ; DOI : https://doi.org/ 10.4000/studifrancesi.5353

Ce document a été généré automatiquement le 18 septembre 2020.

\section{(c)}

Studi Francesi è distribuita con Licenza Creative Commons Attribuzione - Non commerciale - Non opere derivate 4.0 Internazionale. 


\title{
Maurizio Melai, Les Derniers Feux de la tragédie classique au temps du romantisme
}

\author{
Valentina Ponzetto
}

\section{RÉFÉRENCE}

MAURIZIO MELAI, Les Derniers Feux de la tragédie classique au temps du romantisme, Paris, Presses de l'université Paris-Sorbonne, 2015, «Theatrum Mundi», 420 pp.

1 Qui connaît, qui lit encore la tragédie du XIX siècle? Le drame romantique, avec sa fougue, son panache et ses grandes plumes, a remporté la bataille sur son éternelle rivale, l'effaçant presque complètement des mémoires et des histoires littéraires. C'est oublier un corpus d'environ trois cents pièces écrites par une centaine de dramaturges, qui pendant toute la première moitié du XIX siècle ont tenu l'affiche des principaux théâtres officiels, souvent avec succès. Or, à ce jour, aucune étude n'avait été consacrée à dresser un tableau global de ces tragédies tardives.

2 S'intéressant à ce corpus, à l'intérieur duquel il opère une sélection judicieuse de quatre-vingts pièces de vingt-deux auteurs, parmi lesquels se signale surtout Casimir Delavigne, le bel essai de Maurizio Melai vient donc combler un vide dans le panorama critique contemporain. Mieux encore, il vient rectifier quelques idées reçues en matière d'histoire littéraire et d'esthétique dramatique, et rend visibilité et lisibilité à tout un pan du théâtre français.

3 Le premier apport important de ce livre est de repousser les limites chronologiques du genre de la tragédie classique, dont la critique identifiait traditionnellement la fin avec la chute de l'Ancien Régime. Prenant le relais de l'étude de Jean-Pierre Perchellet (L'Héritage classique. La tragédie entre 1680 et 1814, Champion, 2004), Maurizio Melai étudie la survivance, le renouvellement et les multiples avatars successifs de la tragédie sous la Restauration et la Monarchie de Juillet. Pour être plus précis, les limites 
chronologiques de son étude vont de la création de l'Ulysse de Pierre Lebrun le 28 avril 1814, premier succès tragique de la Restauration, à celle de la Rosemonde de Latour de Saint-Ybars en 1854, qui est la dernière pièce française explicitement désignée comme «tragédie». C'est donc bien des «derniers feux de la tragédie classique» qu'il est question, c'est-à-dire du renouveau, des transformations et de la disparition finale d'un genre, celui de la tragédie classique, perçu comme typiquement français et très précisément codifié au cours $d u$ XVII ${ }^{e}$ siècle.

4 À la notion de genre, l'auteur préfère toutefois celle de "code littéraire», défini d'après Francesco Orlando (Illuminismo, barocco e retorica freudiana, Einaudi, 1997) comme l'«ensemble des constantes formelles, structurelles et thématiques qui caractérisent les textes d'une époque historique bien précise», constantes qui sont «le résultat de la transposition artistique de grands paradigmes historiques, ou bien de grandes problématiques socio-politiques dont le code littéraire se fait l'écho» (p.7). À l'approche esthétique qui informe la première section de l'ouvrage, "Poétique et esthétique de la tragédie au XIXe siècle», où le code tragique est analysé dans ses composantes stylistiques, structurelles et dramaturgiques, il joint ainsi une démarche sociocritique. Dans la deuxième section, «Régimes tragiques de symbolisation de l'histoire», les constantes thématiques qui traversent le corpus sont interrogées par le biais de leur rapport à l'histoire et à l'actualité, à travers l'analyse des «stratégies par lesquelles la tragédie transpose, à travers les sujets historiques et riches d'allusions qu'elle traite, les grandes problématiques socio-politiques de son temps» (p. 22).

5 Les buts que l'auteur se propose sont d'abord de "déterminer ce qu'est la forme tragique à l'époque post-napoléonienne, quels sont les principes esthétiques qui la définissent et les motifs éthico-axiologiques qu'elle véhicule» (p. 22); ensuite d'«étudier les liens que la tragédie établit continuellement entre les événements historiques qu'elle met en scène et l'actualité» (p. 23).

6 La tragédie de la Restauration et de la Monarchie de Juillet et, à son image, l'essai de Maurizio Melai sont entièrement traversés de tensions et d'oscillations entre pôles opposés. La première opposition est celle entre la doctrine classique héritée du XvII ${ }^{\mathrm{e}}$ siècle et l'esthétique du drame romantique, qui s'affirme de plus en plus au cours de la période en examen. L'un des grands mérites de cet ouvrage est de montrer, en les mettant constamment en regard, qu'entre tragédie tardive et drame romantique l'opposition est moins nette qu'on ne pourrait le soupçonner. La tragédie est en effet caractérisée sous la Restauration par le même besoin de renouveau, d'assouplissement des règles, d'ouverture à de nouvelles influences et sensibilités que le drame romantique, quoiqu'elle s'adonne à ces expérimentations avec plus de retenue. Ensuite, les deux genres se développent parallèlement, «toujours dans un rapport de continuité et de dialectique féconds» (p.366), connaissant de nombreuses interférences et influences mutuelles. Ainsi, l'auteur montre comment la tragédie évolue dans la tension «entre préservation du goût national et absorption des littératures étrangères», en particulier des modèles de Shakespeare et de Schiller, "entre rattachement au modèle classique français et récupération des paradigmes originels du théâtre grec», notamment des éléments de violence contraires aux bienséances classiques, ou «entre abstraction rhétorique [...] et spectacle visuel, pictural et mimétique» (p. 143), intégrant de plus en plus décors somptueux et pittoresques, costumes qu'on veut «réalistes» et un jeu d'acteurs qui réponde au nouvel idéal de «naturel». Est-il besoin de rappeler, par 
exemple, que Mlle George joue Norma et Lucrèce Borgia, ou que les décors d'Hernani avaient tous déjà servi de décors de tragédies?

7 La contamination graduelle du genre tragique se traduit aussi par l'intégration d'éléments issus du mélodrame, avec son manichéisme axiologique, sa veine pathéticosentimentale et sa sensibilité quotidienne et bourgeoise, ou par l'assouplissement progressif des trois unités aristotéliciennes, en particulier celle de lieu, qui connaît des «réinterprétations extensives» (p. 128) annonciatrices du romantisme. Quant au style, si l'emploi de l'alexandrin n'est jamais remis en question, malgré les foudres de Stendhal, on peut suivre une lente et graduelle évolution vers un rythme plus libre, parfois brisé, et vers un langage plus naturel, qui abandonne un excès d'emphase et de périphrases et finit tardivement par faire une place au «mot propre», comme le fameux «mouchoir» dont Vigny traducteur de Shakespeare s'était fait l'incomparable historien et défenseur dès 1829 .

8 Si le drame romantique a pu trouver son essor, c'est donc aussi parce que la tragédie renouvelée lui avait ouvert la voie dans les goûts du public et dans les pratiques scéniques. Dès lors, la thèse de Maurizio Melai selon laquelle «le drame romantique résulte bien plus d'une évolution que d'une révolution» (p. 365), apparaît prouvée et convaincante.

9 L'autre thèse importante soutenue par l'auteur est que la tragédie se prolonge et a du succès sous la Restauration et la Monarchie de Juillet parce qu'«à travers ses formes conventionnelles elle touche à des thématiques bien présentes à l'esprit des contemporains» et porte à la scène «une actualité socio-politique susceptible d'exciter les passions du public de l'époque» (p. 165). Cette transposition théatrale des grandes questions politiques et sociales n'est cependant pas directe, mais opère à travers une actualisation systématique de l'histoire, et en particulier de l'histoire nationale, mise au service de l'idéologie. Tout peut se charger de sens, depuis le choix du héros et de la période historique jusqu'à la perruque d'un acteur. Il va de soi, par exemple, que choisir la Rome républicaine équivaut facilement à promouvoir un idéal de république et de société démocratique, tandis que le Moyen-Âge français évoquera des valeurs monarchiques, aristocratiques et chevaleresques. De même, mettre en scène dictateurs ou généraux héroïques tels que Sylla, Bélisaire ou Régulus fait référence à la figure de Napoléon (interdit de représentation sur les scènes du temps), tandis que les souverains légitimes de l'histoire médiévale de France renvoient aux Bourbons fraîchement revenus au pouvoir.

Dans la trame dense de renvois et d'actualisations, Maurizio Melai décèle quatre «régimes tragiques de symbolisation de l'histoire», qu'il montre en 'uvre en particulier dans le chapitre consacré à la figure de Napoléon (chap.9). Premièrement un régime allusif, «renvoyant de manière simple et transparente à l'actualité» (p. 370). Ensuite un régime emblématique, plastique et non-verbal, comme dans le cas de Talma prêtant au Sylla de Jouy (1821) le geste, la voix et la coiffure de l'Empereur. Troisièmement un régime mythographique, visant à sublimer le fait historique en fait mythique par de subtiles manipulations. Enfin un régime métaphorique, plus rare et plus subtil, typique du drame romantique plus que de la tragédie et qui consiste à transposer des sujets d'actualité "dans une intrigue historique capable de concentrer des significations modernes». C'est le cas des sujets évoqués dans les derniers chapitres, comme la scène emblématique du couronnement factice ou la peinture désenchantée de souverains cruels, fous, faibles et débauchés, qui remettent gravement en question la légitimité du 
pouvoir monarchique, ou encore comme la contestation de l'autorité religieuse ou paternelle.

$11 \mathrm{Au}$ fil des pages et des analyses, on découvre que la tragédie, forme apparemment archaïque et conservatrice, se fait en réalité sous la Restauration et la Monarchie de Juillet une porte-parole privilégiée de la pensée libérale. De plus, elle ne se contente pas de transposer «les querelles idéologiques de l'époque; elle traduit aussi, à un niveau de lecture plus profond, les inquiétudes et le désenchantement de l'homme moderne» (p. 25).

12 Le seul défaut qu'on pourrait reprocher à l'auteur est un tel enthousiasme pour son objet de recherche qu'il en semble exagérer l'importance. On pourra, par exemple, douter que la tragédie redevienne vraiment «durant quelques décennies [...] l'une des formes d'expression littéraire qui reflètent le mieux l'état d'esprit et la vision du monde des Français» (p.26). Que dire alors du roman, ou justement du drame romantique?

13 Au terme de ce beau parcours le lecteur sortira néanmoins convaincu que la tragédie de la première moitié $\mathrm{du} \mathrm{xIx}^{\mathrm{e}}$ siècle réussit «à parler des contemporains et aux contemporains» (p. 370), et qu'on ne saurait donc plus l'ignorer si l'on veut comprendre pleinement le théâtre et la société du temps. 